\title{
Theories in Second Language Acquisition Need to be
}

\section{Corroborated}

\author{
Nima Shakouri ${ }^{1 *} \&$ Mehdi Shokouhi ${ }^{2}$ \\ ${ }^{1}$ Roudbar Branch, Islamic Azad University, Roudbar, Iran \\ ${ }^{2}$ Department of English, Sari Branch, Islamic Azad University, Sari, Iran \\ * Nima Shakouri, E-mail: nima.shakouri2011@gmail.com
}

\begin{abstract}
Interdisciplinary research is a key thrust for the future. The present paper puts forth that most of the theories born in the last three decades are revitalization of old vocabulary; they are more or less assumption-based. Revitalization of old vocabulary should not be at the expense of discordance but corroboration of each other. In fact, the divergent epistemic orientations in SLA give a competitive nature to SLA. Thus, to the present writers, much of the dialogue concerning the strengths and weaknesses of SLA theories fails to provide a balance between theoretical assumptions and empirically substantiated knowledge.
\end{abstract}

Keywords

SLA, corroboration, discipline, interdisciplinary, transdisciplinary

\section{Introduction}

SLA is a challenging task. Accordingly, Swan (2009) declares, "learning languages is a notoriously complex business, involving the mastery of several different kinds of knowledge and skill" (p. 118). It goes without saying that there is not much consensus among scholars regarding a general view of language acquisition. In this regard, it has been widely informed and suggested by the literature that there always exists a gap between a practitioner's espoused theory and his or her theory-in-action, adding more to the existing challenge in SLA (Argrys \& Schone, 1974). Espoused theory refers to the world view and values people believe their behavior is based on, while theory-in-use denotes the world view and values implied by their behavior. In fact, as to Anderson (1994), educators are unaware that their theories-in-use are not the same as their espoused theories, and people are often unaware of their theories-in-use. To the present writers, the difficulty in measuring SLA has made it a very important task. To put in plain words, "it must always be remembered that things easy to measure are not necessarily important and those not measurable may be very important" (Jacobs, 1977, p. 163).

Recall that SLA is enormously enlarged and raises numerous questions expected to be answered. As Immanuel Kant (cited in Klein, 1998) puts, the human mind suffers from the peculiar fate of being permanently haunted by questions which it cannot answer permanently. In SLA, there is a variety of 
perspectives which are challenging. From Krashen's (1981) input hypothesis which was not in favor of Gregg (2003) who negotiates a high degree of rationality in theory construction in SLA and McLaughlin (1987) lending credence to the legitimacy of a movement toward automaticity to Chomsky's (1957) UG, capturing unity within diversity in language actuation process via principles and parameters, may be all instances of the so-called suffering. In fact, we are haunted in unanswered questions that need to be empirically investigated. Seliger (1982), once, asserts that SLA scholars are flooded with findings difficult to assimilate. He warns "often guilt for the misapplication of such research must rest with the researchers who present findings as if they are absolute and conclusive and ready for direct application to the language classroom" (p. 307).

Insisting on the truism that there is an eternal and inevitable pendulum-oscillating backwards and forwards between theories, so far, suggested, the present writers are in attempt to pave the way towards the corroboration of theories raised in SLA. Since the emergence of a new theory in SLA is not an ad hoc process, cynically speaking, "in the face of some of the more extravagant methodological views which are currently in the air, we need perhaps to bring our feet back into contact with the ground" (Swan, 2009, p. 133). The writer of We Do Need Methods contends "language teaching theorists would do well to consider how they would respond themselves to the kind of methodology that they recommend" (p. 133). In sum, the present work holds that the emergence of a new theory should be oriented towards corroborating the earlier findings.

\section{Theoretical Background}

SLA is a challenging and controversial field (Ellis, 2011). As to Ellis, there is no consensus among educators on the exact position of SLA in applied linguistics. To several scholars (e.g. Long, 1997), SLA is predominantly a cognitive enterprise, while to Firth and Wagner (1997), for instance, it is a social enterprise involving social beings interacting in social settings for social purposes (Lengeling, Hernanez, \& Carvajal, 2011). In fact, SLA “is experiencing a never-ending ontological and theoretical tension" (Yazan, 2012, p. 3).

As a young field, SLA is more theoretical than practical. Among the many theories propagated in SLA, Monitor Theory, as to Klein (1998), is susceptible to be employed practically or better to say has "concrete application" (p. 528). Klein asserts that "[Monitor Theory] has found considerable resonance in the world of education" (p. 528). In an interview conducted by Lengeling, Hernanez, and Carvajal (2011), Rod Ellis asserts that by many of the issues recently addressed in SLA are not clearly of direct relevance to language teaching. In contrast, pointing to the work on Universal Grammar, Ellis claims that the SLA work on Universal Grammar does not have much application to the classroom. Ziabari (2009), also, in an interview with Wayne O'Neil reports that the concept "ineffability", the idea the some things are beyond expression, between languages has little empirical support.

Parallel to the same argument that SLA is a controversial task, in SLA, we face two challenging issues:

(1) the theories suggested in language field are theoretically strong, but empirically weak; and (2) 
scholars feel no need to change their language ideologies. As Goldsmith (2006) maintains, "individuals defend ideologies and resist new conceptual frameworks because ideologies unite group interests and offer political interpretations of how the world is, or how it ought to be" (pp. 264-265). In fact, when educators stick to the tenets of a given theory, they find no reason to change their attitudes until their ideology is consistent with a hard reality (Maftoon \& Shakouri, 2012). Henceforth, the present writers insist that various epistemic orientations on the part of scholars should be highly pertinent to their conception of SLA. Willett's (1995, cited in Yazan, 2012) epistemological commitments, for instance, is aligned with constructivism. In other words, Willet warns "researchers against examining individuals and their interpersonal and socio-cultural contexts separately" (p. 8).

Up until, countless theories have been proposed to explain SLA. Most of them are contradictory, per se. Swain (1995), for instance, goes against Krashen's (1981) input hypothesis and argues in favor of the output hypothesis. She claims practicing the language contributes to the language production. Swain declares "output may stimulate learners to move from the semantic, open ended non-deterministic, strategic processing prevalent in comprehension to the complete grammatical processing needed for accurate production" (p. 128). Along the same vein, Long's (1981) interactionist hypothesis highly motivated by Krashen's (1981) input hypothesis also claims that alone is not sufficient to explain SLA. By the same token, much of the dialogue concerning the strengths and weaknesses of SLA theories fails to provide a balance between theoretical assumptions and empirically substantiated knowledge. Seen from this stance, there are numerous theories in SLA, yet most of them are not close to concrete applications. More importantly, linguists are unwilling to their views because of some findings in SLA fields. Klein (1998), in the same light, maintains that the numerous attempts in SLA cannot be said to "have found strong repercussions in other areas of linguistics; no theoretical linguist has ever changed his or her views because of some findings from SLA research" (p. 532).

\section{On the Corroboration of SLA Theories}

To make more certain, theories need to be corroborated. However, the statement that a theory is highly corroborated does not mean that the theory may be accepted as true (Putman, 1974). Corroboration is achieved when a theory has sustained repeated attempts at falsification. The concept "corroboration" lends support to the claim raised by Karl Popper (cited in Putnam, 1974) that a theory is scientific only if it is refutable by a conceivable event. Every genuine test of a scientific theory, then, is logically an attempt to refute or to falsify it. In fact, when a theory has been corroborated, then this gives us a reason to accept it. By the same token, for a theory in SLA to be accepted, it needs to be corroborated with empirical evidence, and to what extent they suggest new empirically addressable questions. Put differently, Jozef (2001) asserts that new theories in SLA "will need to corroborate findings and test such hypotheses as the following: learning is a gradual process; it is not linear; unless learners are ready to proceed to a new phases of learning, no long-term acquisition takes place" (p. 6). More specifically, VanPatten and Sanz (1995), for instance, corroborated the findings of VanPatten and 
Cadierno (1993) and have shown that the effect of processing instruction is not limited to sentence-level tasks. Fullana and MacKay (2010), also, corroborated previous findings (e.g., Mora, 2006) from formal instruction context that low speech rate and pruned speech rate demonstrated a low level of fluency in English among the Catalan/Spanish bilinguals.

Undeniably, development in theoretical fields is fast. Theories will result in assumptions, and assumptions are hardly to be practically employed. In effect, theoretical ideologies are confined and there is little space to allow us to maneuver. For example, "it is hard to apply such a framework [parameter setting] to some of the central acquisitional phenomena including vocabulary learning or problems with the use of tense forms" (Klein, 1998, p. 531).

Inspired by interdisciplinary perspectives in SLA, Klein holds that too many perspectives in SLA make learners miss the target. Klein's view (i.e., Target Deviation Perspective) is an endeavor to motivate attempts on the part of educators, learners, and teachers to minimize or erase the deviations. In other words, the large number of SLA theories over the past three decades is a source of contention. As Spolsky (1990) claims "new theories do not generally succeed in replacing their predecessors, but continue to coexist with them uncomfortably" (p. 609). In fact, challenging in disciplinary perspectives does not lead to conformity.

While disciplinary depth is respected as a necessity to deal with the SLA theories, they also require what Gardner (2006) suggests a "synthesizing mind" (p. 3). Put simply, to develop more complete pictures, we need to learn how to understand, navigate, and employ multiple ways of knowing (Golding, 2009). In effect, the weft of theories emanated from outside SLA field has to be applied with a clear chain of logic (Cook \& Wei, 2009). Cook and Wei (2009) continue:

An idea resulted from mathematical theory, computer simulation or first language acquisition needs to show its credentials by proving its link to second language teaching through L2 evidence and argument, not imposing itself by fiat, by analogy, or by sheer computer modeling. If one were, say, to adopt knitting theory as a foundation for the applied linguistics of language teaching, one would need to demonstrate how warp and weft account for the basic phenomena of language acquisition and use by showing empirical evidence of their applicability to second language acquisition. (p. 7)

Interdisciplinary research is a key thrust for the future. Like life which is an interdisciplinary phenomenon, SLA cannot be considered as a mere disciplinary issue. As to Canning (2004), a single disciplinary perspective cannot resolve social problems like AIDS, crime, and poverty. Likewise, in SLA, sticking to a single theory cannot contribute to the problem of learning.

In SLA, Larsen-Freeman and Long (1991) maintain that "at least forty theories of SLA have been proposed" (p. 227). Nonetheless, none of them is going to provide a thorough explanation for SLA. Menezes (2013), in this regard, argues "like any other type of learning, language learning is not a linear process, and therefore cannot be deemed as predictable as many models of SLA have hypothesized it is to be" (p. 404). Pienemann's (1998) processability, for instance, is among the theories insisting on the linearity of SLA. According to Pienemannn, there is a predictable sequence of acquisition of the 
procedural skills that are needed for language processing (Jordon, 2004).

Anderson's (1973) operating principles inspired by the work of Slobin (1973) are also linear in nature. Operating principles seek to explain why certain forms appear in L1 and L2 production before others. As Anderson's earlier work focused on the learners' structuring and restructuring of their interlanguage systems, it results in the nativization model (Arroitia, 2005). Accordingly, L2 acquisition consists of two processes: nativization, (i.e., learners conform their input to an internal norm by making hypothesis of the L2 system based on their knowledge of L1 system) and denativization (i.e., learners follow an external norm since they change their interlanguage systems to make them conform to the norms of the input).

In reality, "it is difficult to reject any of the aforementioned theories as all of them seem reasonable but they also seem incomplete, as they do not describe the whole SLA phenomenon, but just parts of it" (Menezes, 2013, p. 407). SLA, per se, is chaotic. It is non-linear, therefore cannot be deemed as predictable. As Menezes puts forth, minimal change in the present condition can cause a very different result. That is, there are so many variable get involved in the process of acquisition. Similarly, Larsen-freeman (1997) declares SLA is complex. Complexity, to her, is "a metaphorical lens through which diverse perspectives can be accommodated, indeed integrated" (p. 173).

It remains to be determined that SLA reached maturity in the 25 years of disciplinary existence (Ortega, 2013). In 21st century, we see a shift in the inclination of scholars towards interdicipliarity and transdisciplinarit. Pishghadam (2011) also maintains English Language Teaching "has grown in maturity over years, establishing an independent identity for itself. It does not play second fiddle to applied linguistics any more" (p. 9). The 20th century, as Halliday (1991) declares, was marked as the golden age of disciplines, each born with its own theories. Nevertheless, the disciplinary movement generated by a field can hardly gain worth for its outside influence (Klein, 1998). Moreover, as Widdowson (2005) puts forth disciplinary knowledge is not as self-contained as they perceived in nature, and as Mahmoodzadeh (2013) goes on to hold, in SLA researchers have embraced and merged several disciplines to come up with a new hybrid discipline called Applied Linguistics with a particular focus on practical aspects of language use.

However, traditional disciplinary approaches have exerted positive impacts on the development of theories in SLA. Regarding the importance of disciplinary approaches, Canning (2014) holds that although the concept of interdisciplinarity is highly dependent upon disiplinarity itself, disciplinarity can inhibit the development of interdisciplinarity. Disciplines provide scientists with frames of reference, methodological approaches, topics of study, theoretical canons, and technologies (Petts, Owens, \& Bulkeley, 2008). Nevertheless, for some of the tasks we expect of scientific enquiry, disciplinary approaches are not sufficient (Stock \& Burton, 2011). Stock and Burton in their study "use the term integrated research as a collective noun to refer to all categories of sustainability research involving integrated multiple disciplines" (p. 1091). Jerneck et al. (Stock \& Burton, 2011) assert that sustainability science is deeply rooted in "rethink[ing] interactions across domains and scales, nature 
and society, science and democracy, the global and the local, as well as the past, present and possible futures" (p. 1091).

Transdisciplinary approaches, unlike disciplinary ones, seek for generating "a theoretical unity of knowledge beyond any one of disciplines or perspectives" (Ortega, 2013, p. 3). In effect, transdiciplinarity is globally open and creative and pursues a way of self-transformation oriented perspective towards knowledge construction (Mahmoodzadeh, 2013). Concerning what SLA can do for the other language sciences rather than what other language sciences can do for SLA, Ortega (2013) uses the term transdisciplinary relevance. Whether SLA has significant repercussions in other areas entails corroborating the hypothesis that SLA contribution to language fields is considerable.

In practicality, "[SLA] status within the various linguistic disciplines is very low" (Klein, 1998, p. 527). Maftoon et al. (2013), also, assert "the impact of SLA on human brain organization is poorly studied" (p. 36), for instance. In a sense, there is a great deal we do not know about the influence of SLA on the brain. However, to the present writers, a deviation is felt in applied linguistics. That is, less has been paid on the exact role of SLA on the brain functioning. Moreover, raising too many assumption-theories in SLA seems to put us in dizziness that makes us ignore the contribution of SLA to other language fields. More importantly, "the understanding of SLA, for instance, can improve the ability of mainstream teachers to serve the culturally and linguistically diverse students in their classrooms" (Hong, 2008, p. 61).

SLA influence on the activity of brain is mesmerizing. "SLA can contribute to the changes in the brain" (Maftoon et al., 2013, p. 35). As a hard-wired system, the brain lacks any software. Maftoon et al. insist that considering SLA as software undeniably contribute to the function and change of the brain. Seliger (1982), in particular, has long put forth "many functions performed by the right hemisphere could considerably play an important role in SLA" (p. 307). Genesee (1982) also contends that the extent to which right hemisphere involves in second language processing is inevitable. By studying SLA, the activity of right-hemisphere increases. In addition, in the study carried out by Martensson (2012), "the cortical thickness and hipocampal volumes of conscript interpreters before and after three months of language studies" (p. 240) are taken into account. Along the same line, Wilson (2013) contends that SLA can enlarge one's hippocampus. Since hippocampus is the center of verbal memory (Kimura, 199), SLA undeniably contributes to the formation of long-term memory (Wilson, 2013).

Though the previous attempts to explain SLA should not be underestimated, recall that SLA is an adaptive system susceptible to adapt itself to different conditions present in both internal and external environments (Menezes, 2013). In fact, "no scientific endeavor can be pleased with the mere discovery of some facts" (Klein, 1998, p. 546). Attempts should be made on what principles can be deduced from what has been discovered. In sum, raising several linguistic assumptions in the air creates a source which is muddling. 


\section{Conclusion}

Most of the studies conducted in the realm of second language acquisition are mostly assumption-based (Altenaishinger, 2003). The naturalistic theory, for instance, is based on the assumption (Altenaichinger, 2003) that language acquisition is innately determined and that we are born with a certain system of language that we can call on later. Krashen's (1981) input hypothesis also merits from the assumption (Altenaichinger, 2003) that holds that for individuals to acquire language, they need to be exposed to the language a bit beyond their current level of competence. In fact, challenging in disciplinarity does not lead to mutuality. In contrast, moving toward interdisciplinarity entails increasing mutuality. There appears to be no mutuality between McLaughlin (1987) and Krashen (1985), for instance. Although success in interdisciplinarity is deeply rooted in having cynical attitudes toward disciplinarity, having a contradictory perspective toward theories raised increase the sense of enmity rather than mutuality. Nonetheless, success will not be achieved if we move in line with solid reality.

Until now, there have been successive and often contradictory views about how best to learn language. According to Swan (2009), "progress is likely to be faster if we are able to remove some of the obstacles that we have allowed to stand in our way" (p. 132). In practicality, progress can be achieved by making more intelligent use of all the resources we have at our disposal. In the study done by Swan, it is claimed that we need, therefore, no so many theories in SLA, but take stock of the existing ones and integrate them into more ideologically neutral and comprehensive approaches. In a sense, understanding of the past appears to be conducive to the current findings. What behaviorists, for instance, have achieved in the past paved the way and provided a theoretical tool, rather than empirical one. Recall that the theoretical tool prepared by behaviorists cannot be compared with that of constructivist. In fact, theories from different paradigms cannot be directly compared with one another because the conflicting assumptions underlying the paradigms are different (Antely, 2010). Thus, it is time that specialists begin to corroborate the key ideas in SLA and attempts should be made towards their falsifications.

\section{References}

Altenaichinger, A. (2002). Theories of second language acquisition. In M. Hanak-Hammerel, \& D. Newby (Eds.), Second language acquisition: The interface between theory and practice (pp. 8-12). Graz: University of Graz.

Anderson, J. R. (1985). Cognitive psychology and its implications. New York: Freeman.

Anderson, L. (1994). Espoused theories and theorie-in-use: Bringing the gap-Breaking through defensive routines with organization development consultants (Unpublished master's thesis). University of Qld.

Antley, M. W. (2010). Toward a metatheoretical integration of developmental paradigms. INTEGRAL REVIEW, 6(3), 175-189.

Argyris, C., \& Schon, D. (1974). Theory in practice: Increasing professional effectiveness. San 
Francisco: Jossey Bass.

Arroitia, B. B. (2005). Negotiation of form: Analysis of feedback and student response in two different contexts. Retrieved in 2015, from http://www.tdx.cat/bitstream/10803/9789/2/clavel.pdf.txt

Boeckx, C. (2006). Linguistic minimalism: Origins, concepts, methods and aims. Oxford: Oxford University Press.

Canning, J. (2004). Interdiscipliarity teaching and learning studies in area studies. Retrieved in 2014, from https://www.llas.ac.uk/resources/paper/2134

Chomsky, N. (1957). Syntactic structures. Paris: Mouton.

Cook, V., \& Wei, L. (2009). Applied linguistics and language teaching in the twenty-first century. In V. Cook, \& L. Wei (Eds.), Contemporary applied linguistics (pp. 1-9). London: Continuum.

Craig, R. (1993). Doubt and certainty. Retrieved in May, 2013, from http://www.Monorealism.com/ reflection/doubt-and-certainty.html?start=1

Firth, A., \& Wagner, J. (1997). On discourse, communication, and (some) fundamental concepts in SLA research. The Modern Language Journal, 81, 285-300.

Fullana, N., \& MacKay, R. A. (2010). L2 fluency in the production of English extemporaneous speech by Catalan/Spanish bilinguals. In M. Wrembel, M. Kul, \& K. Dziubalska-Kolaczyk (Eds.), Achievements and perspectives in SLA of speech: New sounds 2010.

Gardner, H. (2006). Five Minds for the Future. Boston, Mass.: Harvard Business School Press.

Genesee, F. (1082). Experimental neuropsychological research on second language processing. TESOL Quarterly, 16(3), 16-23.

Golding, C. (2009). Integrating the disciplines: Successful interdisciplinary subjects. Melbourne: Centre of the Study of Higher Education.

Goldsmith, P. A. (2006). Learning to understand inequality and diversity: Getting students past ideologies. Teaching Sociology, 34, 263-277.

Gregg, K. R. (2003). SLA Theory: Construction and assessment. In C. J. Doughty, \& M. H. Long (Eds.), The handbook of second language acquisition (pp. 831-865). Oxford: Blackwell.

Hong, Y. (2008). On teaching strategies in second language acquisition. US-China Education Review, $5(1), 61-67$

Jacobs, J. (1977). An external view of neuropsychology and its working milieu. In S. Segalowitz, \& F. Gruber (Eds.), Language development and neurological theory (pp. 155-163). New York: Academic Press.

Jordon, G. (2004). Theory construction in second language acquisition. Amsterdam: John Benjamins Publishing Company.

Jozef, H. (2001). Advanced writing in English as a foreign language: A corpus-based study of processes and products. Pecs: Lingua Franca Csoport.

Kimura, D. (1999). Sex and cognition. Cambridge: The MIT Press.

Klein, W. (1998). The contribution of second language acquisition research. Language Learning, 48, 
$527-550$

Krashen, S. (1981). Principles and practices in second language acquisition. Oxford: Pergamon.

Larsen-Freeman, D. (1997). Chaos/complexity science and second language acquisition. Applied Linguistics, 18(2), 141-165.

Larsen-Freeman, D., \& Long, M. H. (1991). An introduction to second language acquisition research. New York: Longman.

Lengeling, M. M., Hernandez, V. S., \& Carvajal, C. B. (2011). Past, present and future of second language acquisition: An interview with Rod Ellis. MEX TESOL Journal, 35(1), 1-7.

Long, M. (1981). Input, interaction and second language acquisition. In H. Winitz (Ed.), Native language and foreign language acquisition (pp. 259-278). New York: Annals of the New York Academy of Science.

Long, M. (1997). Construct validity in SLA research. The Modern Language Journal, 81, 318-323.

Maftoon, P., \& Shakouri, N. (2012). Aestheticism in the choice of theory: A relativist look. International Journal of Academic Research, 4(6), 237-241.

Maftoon, P., Shakouri, N., \& Nazari, O. (2013). Neurolinguistic approach: A plausible paradigm in SLA. Journal of Advances in Linguistics, 2(1), 35-40.

Mahmoodzadeh, M. (2013). Applied ELT: A paradigm justifying complex adaptive system of language teaching? International Journal of English Language \& Translation Studies, 1(3), 58-74.

Martensson, J., Eriksson. J., Bodammer, N. C., Lindgren, M., Johansson, M., Nyberg, L., \& Lydén M. (2012). Growth of language-related brain areas after foreign language learning. Neuroimage, $15(63), 240-244$.

McLaughlin, B. (1987). Theories of second language learning. London: Arnold.

Menezes, V. (2013). Second Language Acquisition: Reconciling Theories. Open Journal of Applied Sciences, 3, 404-412.

Mora, J. C. (2006). Age effects on oral fluency development. In C. Muñoz (Ed.), Age and the rate of foreign language learning (pp. 68-88). Clevedon: Multilingual Matters.

Ortega, L. (2013). SLA for the 21st century: Disciplinary progress, transdisciplinary, relevance and $\mathrm{Bi} /$ multilingual turn. Language learning, 63, 1-24.

Petts, J., Owens, S., \& Bulkeley, H. (2008). Crossing boundaries: Interdisciplinarity in the context of urban environments. Geoforum, 39, 593-601.

Pienemann, M. (1998). Language processing and second language development: Processability theory. Amsterdam: John Benjamins.

Putnam, H., (1974). The corroboration of theories. In P. A. Schilpp (Ed.), The philosophy of Karl Popper (pp. 221-240). La Salle, IL: Open Court.

Seliger, H. S. (1982). On the possible role of right hemisphere in second language acquisition. TESOL Quarterly, 16(3), 8-15.

Spolsky, B. (1990). Introduction to a colloquium: The scope and form of a theory of second language 
learning. TESOL Quarterly, 24, 609-616.

Stock, P., \& Burton, R. J. F. (2011). Defining terms for integrated (Multi-Inter-Trans-disciplinary) sustainability research. Sustainability, 3, 1090-1113.

Swain, M. (1995). Three functions of output in second language learning. In G. Cook, \& B. Seidlhofer (Eds.), Principle and practice in applied linguistics: Studies in honor of H.G. Widdowson (pp. 125-144). Oxford: Oxford University Press.

Swan, M. (2009). We do need methods. In V. Cook, \& L. Wei (Eds.), Contemporary applied linguistics (pp. 117-136). London: Continuum.

VanPatten, B., \& Sanz, C. (1995). From input to output: Processing instruction and communicative tasks. In F. R. Eckman, D. Highland, P. W. Lee, J. Mileham, \& R. R. Weber (Eds), Second language acquisition theory and pedagogy (pp. 169-186). New Jersey: Lawrence Erlbaum Associates.

Widdowson, H. G. (2005). Applied linguistics, interdisciplinarity, and disparate realities. In P. Bruthiaux, D. Atkinson, W. Eggington, W. Grabe, \& V. Ramanathan (Eds.), Directions in applied linguistics (pp.12-25). Clevedon: Multilingual Matters.

Wilson, K. (2013). An added reason to learn a new language: It increases brain size. Retrieved in 2014, from http:// www.omniglot.com/language/articles/languagelearningbrainsize.htm

Yazan, B. (2012). Divergent philosophical orientations underpinning SLA research. Working Papers in Educational Linguistics, 27(1), 1-8.

Ziabari, K. (2009). Interview: MIT professor Wayne O’Neil, expert on second-language acquisition. Retrieved in 2014, from http://www.thecommentfactory.com/interview-mit-professor-wayneoneil-expert-on-second-language-acquisition-1754/ 